\title{
Outcome of Guillain - Barré Syndrome in Children: A prospective cohort study in a tertiary hospital in Upper Egypt
}

\author{
Abdelrahim Abdrabou Sadek ${ }^{1}$, Ashraf Abou-Taleb ${ }^{2}$, Wafaa Ahmed Ali ${ }^{3}$
}

${ }^{1}$ Assistant Professor, Head of Pediatric Neurology Unit, Pediatric Department, Faculty of Medicine, Sohag University, Sohag, Egypt

${ }^{2}$ Lecturer, Pediatric Department, Faculty of Medicine, Sohag University, Sohag, Egypt

${ }^{3}$ Resident, Pediatric Department, Faculty of Medicine, Sohag University, Sohag, Egypt

\section{Type of article: Original}

\begin{abstract}
Introduction: Guillain-Barre syndrome is the most common cause of acute flaccid paralysis in children, and defined as an acute inflammatory polyneuropathy. The objective of this study was to assess the clinico-laboratory profile, and outcome of Guillain-Barré syndrome in children at Sohag University Hospital.

Methods: This prospective cohort observational study was conducted in 2014-2015. The included children were subjected to through medical history and detailed systemic and neurological examination. Nerve conduction studies and cerebrospinal fluid analysis were done for all patients. Follow up was done at three and six months both clinically and by nerve conduction studies.

Results: This study included 50 patients (27 males / 23 females) with median age of 2.92 years. Upper respiratory tract infections were the most common antecedent infections $(50 \%)$ and the neurological findings were weakness of both lower limbs and pain in all patients (100\%) followed by sphincteric dysfunction $(26 \%)$ while cranial neuropathies were found in $4 \%$. Nerve conduction study revealed that acute inflammatory demyelinating polyradiculoneuropathy was found in $52 \%$ of cases, acute motor axonal neuropathy in $36 \%$ of cases, whereas acute motor-sensory axonal neuropathy was found in $6 \%$ of cases. The outcome was good in about $78 \%$ of cases, Hughes motor scale revealed that $58 \%$ were healthy, $18 \%$ had minor signs or symptoms, $12 \%$ walked without support, $6 \%$ walked with support, and $6 \%$ were bed ridden.

Conclusion: The outcome was favorable, although a minority of patients suffered neurological deficit. Immediate administration of intravenous immunoglobulin reduced mortality and disability.
\end{abstract}

Keywords: Guillain-Barré syndrome (GBS); Nerve conduction study; Intravenous immunoglobulin (IVIg)

\section{Introduction}

Guillain-Barré syndrome (GBS) is the most common cause of acute flaccid paralysis in children, and defined as an acute inflammatory polyneuropathy characterized by rapidly progressive, essentially symmetric weakness and areflexia in a previously otherwise healthy child $(1,2)$. The incidence of GBS has been estimated to be between 0.34 and 1.34/100 000. GBS in children and adolescents is a disease affecting mainly the younger age groups (3). It is associated with a mortality rate of $5-15 \%$ and approximately $30 \%$ of the patients require mechanical ventilation some time during their illness $(4,5)$. The diagnosis of GBS is based primarily on the clinical evaluation and the exclusion of important possible alternative diagnoses. Classically in GBS the weakness starts in the lower limbs then follows an ascending course over hours or days (6). Supportive investigations include CSF examination, and nerve conduction studies (NCS). Both intravenous immunoglobulins (IVIg) and plasma exchange have been the first-line therapy for GBS patients (7). About 5 to $10 \%$ of GBS patients deteriorate after initial improvement or stabilization following IVIg treatment, a condition named "treatment-related clinical fluctuation" $(8,9)$. Pediatric GBS is

\section{Corresponding author:}

Assistant Professor Dr. Abdelrahim Abdrabou Sadek, Pediatric Department, Faculty of Medicine, Sohag University, Sohag, Egypt. Tel.: +20.1065067057; Fax: +20.934602963, E-mail: abdoneurology@yahoo.com, abdelreheam_sadek@med.sohag.edu.eg

Received: June 05, 2016, Accepted: October 09, 2016, Published: December 2016

iThenticate screening: October 09, 2016, English editing: November 13, 2016, Quality control: December 06, 2016 (C) 2016 The Authors. This is an open access article under the terms of the Creative Commons Attribution-NonCommercialNoDerivs License, which permits use and distribution in any medium, provided the original work is properly cited, the use is non-commercial and no modifications or adaptations are made. 
generally associated with a shorter illness and more complete recovery than is typical in adults (10-12). Studies in Upper Egypt about GBS are few, so the objectives of this study were analysis of the clinical and laboratory findings, in addition to evaluating the outcome of 50 children having GBS at Sohag University Hospital.

\section{Material and Methods}

\subsection{Study design}

This was a prospective cohort observational study carried out for a period of one year (from the 1st of October 2014 to the end of September 2015) at the Pediatric department, Sohag University Hospital, Sohag, Upper Egypt.

\subsection{Selection criteria}

\subsubsection{Inclusion criteria}

All infants and children presented with acute flaccid paralysis and suspected to have GBS were included.

\subsubsection{Exclusion criteria}

Children with other causes of acute flaccid paralysis, such as transverse myelitis, hypokalemic paralysis. Also central nervous system infections were excluded from the study depending on absence of any encephalopathy or CSF characteristics.

\subsection{Ethical consideration}

The protocol of the study was approved by the Research Ethics Committee at Sohag Faculty of Medicine. Informed consent was obtained from parents of all enrolled subjects. The work has been carried out in accordance with The Code of Ethics of The World Medical Association (Declaration of Helsinki) for experiments on humans.

\subsection{Data collection methods}

Diagnosis of GBS was made clinically by a pediatrician and a pediatric neurologist based on the history given by the parents, and observation of clinical data. Patients with clinical diagnosis of GBS were subjected to the following; thorough clinical history, full clinical examination with detailed neurological examination focusing on (the conscious level, cranial nerves, reflexes, muscle tone, muscle power, motor and sensory system). The following investigations were done for all patients; cerebrospinal fluid analysis (CSF), electrophysiological studies, and magnetic resonance imaging of the dorsolumbar spine to exclude spinal lesions and transverse myelitis. Electrophysiological studies were done using Neurosoft Mod: Neuro-EMG MI CRO-Russian during one to two weeks after initiation of symptoms. Motor nerve conduction study conducted by stimulating the common peroneal nerve (CPN), posterior tibial nerve (PTN), median and ulnar nerves to assess compound muscle action potentials (CMAPs), which include onset latency, amplitude and conduction velocity. Sensory nerve conduction study was done to estimate sural, median and ulnar sensory nerve action potentials (SNAPs). F wave latency was also defined. The electrophysiological diagnosis of GBS was based upon the criteria suggested by many researchers (13-15). According to nerve conduction study (NCS), the patients were classified into acute inflammatory demyelinating polyradiculoneuropathy (AIDP), acute motor axonal neuropathy (AMAN), acute motor-sensory axonal neuropathy (AMSAN), and normal nerve conduction study (13-15). All patients received intravenous immunoglobulin 400 $\mathrm{mg} / \mathrm{kg} /$ day for five days (16). Outcome at 3 and 6 months was assessed both clinically (by detailed neurological examination), and by electrophysiology. Evaluation of motor disability was done using Medical Research Council (MRC) scale and Hughes motor scale (HMS) (17).

\subsection{Statistical analysis}

The data was subjected to statistical analysis and tabulation using SPSS version 18 (SPSS Inc., Chicago, Illinois, USA). P-value is considered significant if less than 0.05 then the results were presented to fulfill the objectives of the study.

\section{Results}

The study included 50 patients with median age of 2.92 years (range from 7 months to 11 years). Out of them 27 $(54 \%)$ were males and $23(46 \%)$ were females with male to female ratio 1.1:1. Twenty-three cases $(46 \%)$ came from urban areas while $27(54 \%)$ cases from rural areas, and urban to rural ratio was 1:1.1. Antecedent infections were found in 33 patients $(66 \%)$, of them, $25(76 \%)$ had upper respiratory tract infection, gastroenteritis was present in seven patients $(21 \%)$ while urinary tract infection was present in only one patient $(3 \%)$ (Table 1). Concerning clinical presentations of the patients; weakness of both lower limbs and pain were the main complaints in almost all patients. Both urinary and stool incontinence were present in $26 \%$ of patients (Table 1). Initially, cranial nerve examination was abnormal in two cases $(4 \%)$ while at 6 months follow up only one case had abnormal cranial nerve 
http://www.ephysician.ir

examination. Hypotonia was initially present in all patients, at 3 months interval about $98 \%$ of patients were hypotonic whereas at 6 months interval about $96 \%$ of patients were hypotonic (Table 2).

Table 1 Socio-demographic characteristic of studied population

\begin{tabular}{|c|c|c|c|}
\hline \multicolumn{3}{|l|}{ Variables } & Summary statistics \\
\hline \multirow[t]{2}{*}{ Age (year) } & \multicolumn{2}{|l|}{ Mean (SD) } & $3.07(1.97)$ \\
\hline & \multicolumn{2}{|l|}{ Median (range) } & $2.92(0.58-11)$ \\
\hline \multirow[t]{2}{*}{ Sex; n $(\%)$} & \multicolumn{2}{|l|}{ Females } & $23(46.00)$ \\
\hline & \multicolumn{2}{|l|}{ Males } & $27(54.00)$ \\
\hline \multirow[t]{2}{*}{ Residence; n (\%) } & \multicolumn{2}{|l|}{ Urban } & $23(46.00)$ \\
\hline & \multicolumn{2}{|l|}{ Rural } & $27(54.00)$ \\
\hline \multirow[t]{4}{*}{ Antecedent infections (In 33 patients only) } & \multirow[t]{2}{*}{ Gastroenteritis } & $\mathrm{n}(\%)$ & $7(21.00)$ \\
\hline & & Mean duration (SD) & $4.14(3.53)$ \\
\hline & \multicolumn{2}{|c|}{ Respiratory infections; $\mathrm{n}(\%)$} & $25(76.00)$ \\
\hline & \multicolumn{2}{|c|}{ Urinary tract infection; $\mathrm{n}(\%)$} & $1(3.00)$ \\
\hline \multirow{2}{*}{ Weakness of lower limb } & \multicolumn{2}{|c|}{ Acute onset; $\mathrm{n}(\%)$} & $2(4.00)$ \\
\hline & \multicolumn{2}{|c|}{ Gradual onset; $\mathrm{n}(\%)$} & $48(96.00)$ \\
\hline \multicolumn{3}{|l|}{ Pain (Acute Onset); $\mathrm{n}(\%)$} & $50(100)$ \\
\hline \multicolumn{3}{|c|}{ Autonomic dysfunction (Urine and stool incontinence); $\mathrm{n}(\%)$} & $13(26.00)$ \\
\hline \multirow[t]{4}{*}{ Nerve conduction study; $\mathrm{n}(\%)$} & \multicolumn{2}{|l|}{ AIDP } & $26(52.00)$ \\
\hline & \multicolumn{2}{|l|}{ AMAN } & $18(36.00)$ \\
\hline & \multicolumn{2}{|l|}{ AMSAN } & $3(6.00)$ \\
\hline & \multicolumn{2}{|l|}{ Normal } & $3(6.00)$ \\
\hline
\end{tabular}

Table 2. Examination of the nervous system in the studied population

\begin{tabular}{|c|c|c|c|c|c|}
\hline \multicolumn{2}{|l|}{ Variables } & Initial; n (\%) & At 3 months; n (\%) & At 6 months; n (\%) & p-value \\
\hline \multicolumn{2}{|c|}{ Cranial neuropathy } & $2(4.00)$ & $2(4.00)$ & $1(2.00)$ & 0.81 \\
\hline \multicolumn{2}{|c|}{ Muscle bulk (Normal) } & $50(100.000)$ & $50(100.000)$ & $50(100.000)$ & 1.00 \\
\hline \multicolumn{2}{|c|}{ Fasciculations or involuntary movements } & $1(2.00)$ & $1(2.00)$ & 0 & 0.60 \\
\hline \multicolumn{2}{|l|}{ Hypotonia } & $50(100.00)$ & $49(98.00)$ & $48(96.00)$ & 0.36 \\
\hline \multirow[t]{4}{*}{ Muscle power } & $2 / 5$ & $2(4.00)$ & $1(2.00)$ & 0 & \multirow[t]{4}{*}{$<0.0001$} \\
\hline & $3 / 5$ & $41(82.00)$ & $39(78.00)$ & $4(8.00)$ & \\
\hline & $4 / 5$ & $7(14.00)$ & $9(18.00)$ & $9(18.00)$ & \\
\hline & Normal & 0 & $1(2.00)$ & $37(74.00)$ & \\
\hline \multicolumn{2}{|c|}{ Impaired coordination } & $50(100.00)$ & $50(100.00)$ & $50(100.00)$ & 1.00 \\
\hline
\end{tabular}

We found significant improvement of superficial reflexes (abdominal, anal, cremasteric, and planter reflexes) on follow up. Also significant improvement in muscle stretch reflexes of lower limbs (knee, Achilles reflexes) was noted (Table 3). Regarding CSF analysis, the mean white blood count (WBCs)/mm3 was 1.8 (1.91), while mean CSF protein (mg/dl) was 76.86 (27.68), furthermore the mean CSF glucose was 45.89 (16.43). Electrophysiological study revealed the following subtypes of GBS; acute inflammatory demyelinating polyradiculoneuropathy (AIDP) in $52 \%$ of cases, acute motor axonal neuropathy (AMAN) in 36\%, acute motor-sensory axonal polyneuropathy (AMSAN) in $6 \%$ of cases and $6 \%$ of cases had normal NCS study. At 6 months, $2 \%$ were AIDP and $98 \%$ had normal NCS (Table 1). Regarding clinical presentations of different subtypes of GBS, weakness of lower limbs was present in all patients. However, autonomic dysfunction including sphincteric problems was found in $23.08 \%$ of AIDP cases, $16.67 \%$ of AMAN cases, $66.67 \%$ of AMSAN cases and in $66.67 \%$ of cases with normal electrophysiological study (Table 4). Cranial nerve examination was abnormal in 3.85\% of AIDP cases and 5.56\% of AMAN cases. However it was normal in all AMSAN cases and all cases with normal NCS (Table 5). All patients treated with IVIg with a mean period between disease onset and treatment was $16.46 \pm 8.12$ days. Recurrence of GBS occurred in $12(24 \%)$ patients. Out of them, $7(58.33 \%)$ were females and $5(41.67 \%)$ were males. After 6 months, MRC sum score showed significant improvement as $74 \%$ of the cases reached 60 and the outcome was good in about $78 \%$ of cases, moderate in $16 \%$ and poor in $6 \%$. Finally Hughes motor scale (HMS) revealed that $58 \%$ of cases were healthy, $18 \%$ had minor signs or symptoms, $12 \%$ walked without support, $6 \%$ walked with support and $6 \%$ were bed ridden (Table 6). 
Table 3. Reflexes Examination

\begin{tabular}{|c|c|c|c|c|c|c|}
\hline \multicolumn{3}{|l|}{ Variables } & Initial; n (\%) & At 3 months; & At 6 months; & p-value \\
\hline \multirow{11}{*}{$\begin{array}{l}\text { Superficial } \\
\text { reflexes }\end{array}$} & \multirow[t]{3}{*}{ Abdominal } & Normal & 0 & 0 & $49(98.00)$ & \multirow[t]{3}{*}{$<0.0001$} \\
\hline & & Hyporeflexia & $49(98.00)$ & $50(100.00)$ & $1(2.00)$ & \\
\hline & & Areflexia & $1(2.00)$ & 0 & 0 & \\
\hline & \multirow[t]{3}{*}{ Anal } & Normal & 0 & 0 & $49(98.00)$ & \multirow{3}{*}{$<0.0001$} \\
\hline & & Hyporeflexia & $49(98.00)$ & $50(100.00)$ & $1(2.00)$ & \\
\hline & & Areflexia & $1(2.00)$ & 0 & 0 & \\
\hline & \multirow{3}{*}{$\begin{array}{l}\text { Cremasteric in } \\
\text { males }\end{array}$} & Normal & 0 & 0 & $27(54.00)$ & \multirow[t]{3}{*}{$<0.0001$} \\
\hline & & Hyporeflexia & $26(52.00)$ & $28(56.00)$ & 0 & \\
\hline & & Areflexia & $24(48.00)$ & $22(44.00)$ & $23(46.00)$ & \\
\hline & \multirow[t]{2}{*}{ Planter } & Negative Babinski & $41(82.00)$ & $39(78.00)$ & $40(80.00)$ & \multirow[t]{2}{*}{0.88} \\
\hline & & Positive Babinski & $9(18.00)$ & $11(22.00)$ & $10(20.00)$ & \\
\hline \multirow{9}{*}{$\begin{array}{l}\text { Muscle } \\
\text { stretch } \\
\text { reflexes } \\
\text { (upper limb) }\end{array}$} & \multirow[t]{3}{*}{ Biceps } & Normal & $48(96.00)$ & $48(96.00)$ & $50(100.00)$ & \multirow[t]{3}{*}{0.73} \\
\hline & & Hyporeflexia & $1(2.00)$ & $1(2.00)$ & 0 & \\
\hline & & Areflexia & $1(2.00)$ & $1(2.00)$ & 0 & \\
\hline & \multirow[t]{3}{*}{ Triceps } & Normal & $48(96.00)$ & $48(96.00)$ & $50(100.00)$ & \multirow[t]{3}{*}{0.73} \\
\hline & & Hyporeflexia & $1(2.00)$ & $1(2.00)$ & 0 & \\
\hline & & Areflexia & $1(2.00)$ & $1(2.00)$ & 0 & \\
\hline & \multirow{3}{*}{ Brachioradialis } & Normal & $48(96.00)$ & $48(96.00)$ & $50(100.00)$ & \multirow[t]{3}{*}{0.73} \\
\hline & & Hyporeflexia & $1(2.00)$ & $1(2.00)$ & 0 & \\
\hline & & Areflexia & $1(2.00)$ & $1(2.00)$ & 0 & \\
\hline \multirow{6}{*}{$\begin{array}{l}\text { Muscle } \\
\text { stretch } \\
\text { reflexes } \\
\text { (lower limb) }\end{array}$} & \multirow[t]{3}{*}{ Knee } & Normal & 0 & 0 & $49(98.00)$ & \multirow[t]{3}{*}{$<0.0001$} \\
\hline & & Hyporeflexia & $49(98.00)$ & $49(98.00)$ & $1(2.00)$ & \\
\hline & & Areflexia & $1(2.00)$ & $1(2.00)$ & 0 & \\
\hline & \multirow[t]{3}{*}{ Achilles } & Normal & 0 & 0 & $49(98.00)$ & \multirow[t]{3}{*}{$<0.0001$} \\
\hline & & Hyporeflexia & $49(98.00)$ & $49(98.00)$ & $1(2.00)$ & \\
\hline & & Areflexia & $1(2.00)$ & $1(2.00)$ & 0 & \\
\hline
\end{tabular}

Table 4. Comparison among different types of nerve conduction velocity according to presenting symptoms of studied population

\begin{tabular}{|l|l|l|l|l|l|l|}
\hline Variables & $\begin{array}{l}\text { AIDP } \\
(\mathrm{n}=26)\end{array}$ & $\begin{array}{l}\text { AMAN } \\
(\mathrm{n}=18)\end{array}$ & $\begin{array}{l}\text { AMSAN } \\
(\mathrm{n}=3)\end{array}$ & $\begin{array}{l}\text { Normal NCS } \\
(\mathrm{n}=3)\end{array}$ & $\begin{array}{l}\mathrm{p}- \\
\text { value }\end{array}$ \\
\hline $\begin{array}{l}\text { Weakness of lower } \\
\text { limb; } \mathrm{n}(\%)\end{array}$ & Acute onset & $1(3.85)$ & 0 & 0 & $1(33.33)$ & 0.06 \\
\cline { 2 - 7 } & Gradual onset & $25(96.15)$ & $18(100)$ & $3(100)$ & $2(66.66)$ & \\
\hline Pain (acute onset); $\mathrm{n}(\%)$ & $26(100)$ & $18(100)$ & $3(100)$ & $3(100)$ & 1.00 \\
\hline Urine and stool incontinence; $\mathrm{n}(\%)$ & $6(23.08)$ & $3(16.67)$ & $2(66.67)$ & $2(66.67)$ & 0.11 \\
\hline
\end{tabular}

Table 5. Comparison among different subtypes of GBS according to motor system examination

\begin{tabular}{|c|c|c|c|c|c|c|}
\hline \multicolumn{2}{|l|}{ Variables } & $\begin{array}{l}\text { AIDP } \\
(\mathrm{n}=26)\end{array}$ & $\begin{array}{l}\text { AMAN } \\
(\mathrm{n}=18)\end{array}$ & $\begin{array}{l}\text { AMSAN } \\
(\mathrm{n}=3)\end{array}$ & $\begin{array}{l}\text { Normal } \\
(\mathrm{n}=3)\end{array}$ & $\begin{array}{l}\mathrm{p}- \\
\text { value }\end{array}$ \\
\hline \multirow[t]{2}{*}{ Cranial nerves; n (\%) } & Normal & $25(96.15)$ & $17(94.44)$ & $3(100)$ & $3(100)$ & 0.95 \\
\hline & Abnormal & $1(3.85)$ & $1(5.56)$ & 0 & 0 & \\
\hline \multicolumn{2}{|l|}{ Muscle bulk (normal) } & $26(100)$ & $18(100)$ & $3(100)$ & $3(100)$ & 1.00 \\
\hline \multirow[t]{2}{*}{$\begin{array}{l}\text { Fasciculations or involuntary } \\
\text { movements; } \mathrm{n}(\%)\end{array}$} & $\begin{array}{l}\text { Not } \\
\text { present }\end{array}$ & $25(96.15)$ & $18(100)$ & $3(100)$ & $3(100)$ & \multirow[t]{2}{*}{0.82} \\
\hline & Present & $1(3.85)$ & 0 & 0 & 0 & \\
\hline \multicolumn{2}{|l|}{ Hypotonia; n (\%) } & $26(100)$ & $18(100)$ & $3(100)$ & $3(100)$ & 1.00 \\
\hline \multirow[t]{3}{*}{ Muscle power; n (\%) } & $2 / 5$ & $2(7.69)$ & 0 & 0 & 0 & \multirow[t]{3}{*}{0.07} \\
\hline & $3 / 5$ & $16(61.54)$ & $18(100)$ & $3(100)$ & $3(100)$ & \\
\hline & $4 / 5$ & $8(30.77)$ & 0 & 0 & 0 & \\
\hline \multicolumn{2}{|l|}{ Coordination (Impaired) } & $26(100)$ & $18(100)$ & $3(100)$ & $3(100)$ & 1.00 \\
\hline
\end{tabular}


http://www.ephysician.ir

Table 6. Outcome after 6 months

\begin{tabular}{|c|c|c|c|c|c|}
\hline \multicolumn{2}{|l|}{ Variables } & \multicolumn{4}{|l|}{$\mathrm{n}(\%)$} \\
\hline \multirow[t]{3}{*}{ Good outcome } & Full recovery & \multirow{3}{*}{\multicolumn{4}{|c|}{$\begin{array}{l}33(66) \\
0 \\
6(12)\end{array}$}} \\
\hline & Minor deficit upper limb & & & & \\
\hline & Minor deficit lower limb & & & & \\
\hline \multicolumn{2}{|c|}{ Moderate (Moderate and independent) outcome } & \multicolumn{4}{|l|}{$8(16)$} \\
\hline \multirow[t]{2}{*}{ Poor outcome } & Chair bound & \multicolumn{4}{|l|}{$3(6)$} \\
\hline & Bed ridden & \multicolumn{4}{|l|}{0} \\
\hline $\begin{array}{l}\text { Hughes motor } \\
\text { scale (HMS) }\end{array}$ & $\begin{array}{l}\text { (0) Asymptomatic } \\
\text { (1) Mild signs or symptoms but able to } \\
\text { run } \\
\text { (2) Able to walk unaided for } 5 \text { meters } \\
\text { (3) Able to walk } 5 \text { meters with support } \\
\text { (4) Bed ridden or chair bound } \\
\text { (5) Requiring ventilatory assistance } \\
\text { (6) Death }\end{array}$ & \multicolumn{4}{|l|}{$\begin{array}{l}29(58) \\
9(18) \\
6(12) \\
3(6) \\
3(6) \\
0(0.0) \\
0(0.0)\end{array}$} \\
\hline \multirow{2}{*}{$\begin{array}{l}\text { Medical } \\
\text { Research } \\
\text { Council } \\
\text { (MRC) sum- } \\
\text { score }\end{array}$} & Score & Initial & At 3 months & At 6 months & p-value \\
\hline & $\begin{array}{l}51-60 \\
41-50 \\
31-40 \\
\geq 30\end{array}$ & $\begin{array}{l}0(0 \%) \\
7(14 \%) \\
41(82 \%) \\
2(14 \%)\end{array}$ & $\begin{array}{l}1(2 \%) \\
9(18 \%) \\
39(78 \%) \\
1(2 \%)\end{array}$ & $\begin{array}{l}37(74 \%) \\
9(18 \%) \\
4(8 \%) \\
0(0 \%)\end{array}$ & $<0.0001$ \\
\hline
\end{tabular}

\section{Discussion}

Infants and children presenting with acute flaccid paralysis represent a relatively common emergency in outpatients and inpatients divisions of the Pediatric department. The aims of evaluation of these patients were to clarify the diagnosis and to give an appropriate therapy. Analysis of cerebrospinal fluid (CSF) and electrophysiological study are essential for accurate diagnosis of GBS (18). In the present study, we performed a clinical analysis and reviewed the data of 50 infants and children presented with GBS. The median age was 2.92 years and the majority of cases belonged to the youngest age group (1 year to 2 years) and this was relatively similar to the Arab country study (19) (median age was 3.5 years) and lower than other reports $(20,21)$. Male to female ratio was 1.1:1 suggesting a relative male predominance. This finding was consistent with other reports (20-22). The prevalence of GBS was sporadic with urban to rural ratio of 1.1:1. This finding was in agreement with other reports (23), furthermore, in the study done by van Doorn et al., they found that GBS was sporadic and small epidemics had been reported (11). In our study, antecedent infections were encountered in $66 \%$ of cases and respiratory tract infections were the most frequent $(76 \%)$ followed by gastroenteritis (21\%). This finding was consistent with other reports (4, 20-24). The neurological manifestations were weakness of both lower limbs (100\%), hyporeflexia $(98 \%)$, areflexia (2\%), and cranial nerve involvement $(2 \%)$, this data came to agreement with other reports (20-23). The analysis of CSF showed cytoalbuminous dissociation and this was in accordance with other reports (23) in AIDP subtype but lower in the other subtypes. According to nerve conduction studies, we found that AIDP was present in $52 \%$ of patients, AMAN in $36 \%$ of patients, AMSAN in $6 \%$ of patients and only $6 \%$ of patients had normal nerve conduction study. In a similar report, AIDP was present in $44 \%$ of patients, AMAN in 35\% of patients, AMSAN in $21 \%$ of patients and $1 \%$ only had normal nerve conduction study (25), furthermore comparable results were obtained by other studies $(2,21,23)$ however other reports (22) showed different data as the axonal type was the most frequent pattern. All forms of GBS presented with weakness of lower limbs. Cranial nerve involvement was present in $3.85 \%$ of AIDP patients and in 5.56\% of AMAN patients, whereas there was no affection of cranial nerves, neither in AMSAN cases nor in cases with normal NCS. Similar data were obtained in other reports (23) meanwhile in other study (21), cranial neuropathies were more common in the axonal subtype. In our study we reported sphincteric dysfunction with urine and stool incontinence in $23.08 \%$ of AIDP patients, $16.67 \%$ of AMAN patients, $66.67 \%$ of AMSAN patients, and $66.67 \%$ of patients with normal NCS. Comparable results were obtained by Tekgul et al., (2003) as mild autonomic dysfunctions (urinary dysfunction, abnormal sweating) were seen in only $20 \%$ of the AIDP group and severe autonomic dysfunctions were observed in $80 \%$ of the AMSAN group (23) however urinary problems were more common in the demyelinating group in other reports (21). Although GBS is a self-limiting illness in many patients, it can be associated with severe morbidity and mortality in patients with fulminant course. In our study a standard IVIg therapy was administered at hospital admission for all patients with any grade of the disease followed by physiotherapy, but there was no consensus as to which patients would benefit from IVIg 
treatment and what the effective dose is. Data from similar reports (26) found that IVIg had shortened the time to first improvement and to regain independent walking. They reported that the patients who had just lost the ability to walk had experienced the greatest benefit from IVIg, and the patients who were tetraplegic and/or ventilated did not respond to treatment. They applied a standard IVIg therapy on admission for all patients with any grade of disease (26). In this work, recurrence or treatment-related fluctuation (TRF) was noticed in 12 patients (24\%). Our data was higher than other reports $(23,27)$ that showed recurrence in $3.5 \%$ and $9 \%$ respectively. This could be explained by higher exposure to infectious diseases in our community that trigger the disease. The prognosis of GBS was usually favorable and the majority of the patients fully recovered or had only minor deficits. In our study, the outcome of GBS was good in $78 \%$ of cases, moderate in $16 \%$ whereas only $6 \%$ had poor outcome. According to Hughes motor scale (HMS), the majority of patients $(58 \%)$ were healthy while $18 \%$ had minor signs or symptoms. These findings were consistent with other reports $(26,28)$. Furthermore, comparable studies demonstrated almost similar findings. In one report published by Verma et al., they found good functional outcome in $72.2 \%$ of patients, of which $30 \%$ had completely recovered while $27.8 \%$ had poor functional outcome (22). In another report (26), 75\% of patients were free of symptoms, $21 \%$ suffered minor residual symptoms, while $4 \%$ were severely disabled. Although $81.4 \%$ recovered satisfactorily, eight were persistently disabled (29). Outcome was excellent in a childhood study (20) with full recovery or minimal symptoms in $87.5 \%$ of children at one year, and reached $95 \%$ after two years. In a review by van Doorn it was concluded that, after 6 months $20 \%$ of patients are still unable to walk (11).

\section{Conclusions}

GBS should be suspected in all cases presenting with acute flaccid paralysis in different age groups, and immediate intervention by administration of IVIg therapy can reduce morbidity and mortality, and ultimately can reduce chronic neurological disability. We recommend that this idea of research should be repeated in the future on a larger number of cases including different age groups in our locality with better resources, and longer follow up.

\section{Acknowledgments:}

Authors wish to thank the children and their parents for their participation in this study.

\section{Conflict of Interest:}

There is no conflict of interest to be declared.

\section{Authors' contributions:}

AS and AA conceived the study, carried out its designing, coordinated the implementation, and drafted the manuscript. WA participated in the design of the study, analysis and interpretation of data. WA was responsible for interpretation of laboratory and radiological data of patients and revision of the manuscript. All authors read and approved the final manuscript.

\section{References:}

1) Yuki N, Hartung HP. Guillain-Barré syndrome. N Engl J Med. 2012; 366(24): 2294-304. doi: 10.1056/NEJMra1114525. PMID: 22694000.

2) Asbury AK. New concepts of Guillain-Barre' syndrome. J Child Neurol. 2000; 15(3): 183-91. doi: 10.1177/088307380001500308. PMID: 10757475.

3) Hughes RA, Cornblath DR. Guillain-Barré syndrome. Lancet. 2005; 366(9497): 1653-66. doi: 10.1016/S0140-6736(05)67665-9.

4) Lawn ND, Fletcher DD, Henderson RD, Wolter TD, Wijdicks EF. Anticipating mechanical ventilation in Guillain-Barre syndrome. Arch Neurol. 2001; 58(6): 893-8. doi: 10.1001/archneur.58.6.893.

5) Cosi V, Versino M. Guillain-Barre syndrome. Neurol. 2006; 27(Suppl.1): S47-51.

6) Winer JB, Hughes RA, Anderson MJ, Jones DM, Kangro H, Watkins RP. A prospective study of acute idiopathic neuropathy. II. Antecedent events. J Neurol Neurosurg Psychiatry. 1988; 51(5): 613-8. doi: 10.1136/jnnp.51.5.613. PMID: 3404161, PMCID: PMC1033063.

7) Orlikowski D, Porcher R, Sivadon-Tardy V, Quincampoix JC, Raphael JC, Durand MC, et al. GuillainBarré syndrome following primary cytomegalovirus infection: a prospective cohort study. Clin Infect Dis. 2011; 52(7): 837-44. doi: 10.1093/cid/cir074. PMID: 21427390.

8) Garssen MP, Van Koningsveld R, Van Doorn PA, Merkies IS, Scheltens-de Boer M, Van Leusden JA, et al. Treatment of Guillain-Barre syndrome with mycophenolatemofetil: a pilot study. J Neurol Neurosurg Psychiatry. 2007; 78(9): 1012-3. doi: 10.1136/jnnp.2006.102731. PMID: 17702789, PMCID: PMC2117875. 
9) Overell JR, Hsieh ST, Odaka M, Yuki N, Willison HJ. Treatment for Fisher syndrome, Bickerstaff's brainstem encephalitis andrelated disorders. Cochrane Database Syst Rev. 2007; 1: CD004761. doi: 10.1002/14651858.CD004761.pub2. PMID: 17253522.

10) Dodd CN, Romio SA, Black S, Vellozzi C, Andrews N, Sturkenboom M, et al. International collaboration to assess the risk of Guillain Barré Syndrome following Influenza A (H1N1) 2009 monovalent vaccines. Vaccine. 2013; 31(40): 4448-58. doi: 10.1016/j.vaccine.2013.06.032. PMID: 23770307.

11) Van Doorn PA. Diagnosis, treatment and prognosis of Guillain-Barré syndrome (GBS). Presse Med. 2013; 42(6 Pt 2): e193-201. doi: 10.1016/j.lpm.2013.02.328. PMID: 23628447.

12) Khandaker G, Zurynski Y, Buttery J, Marshall H, Richmond PC, Dale RC, et al. Neurologic complications of influenza $\mathrm{A}(\mathrm{H} 1 \mathrm{N1}$ )pdm09: surveillance in 6 pediatric hospitals. Neurology. 2012; 79(14): 1474-81. doi: 10.1212/WNL.0b013e31826d5ea7. PMID: 22993280, PMCID: PMC4098823.

13) Ho TW, Mishu B, Li CY, Gao CY, Cornblath DR, Griffin JW, et al. Guillain-Barré syndrome in northern China. Relationship to Campylobacter jejuni infection and anti-glycolipid antibodies. Brain. 1995; 118( Pt 3): 597-605. doi: 10.1093/brain/118.3.597. PMID: 7600081 .

14) Hadden RD, Cornblath DR, Hughes RA, Zielasek J, Hartung HP, Toyka KV, et al. Electrophysiological classification of Guillain-Barré syndrome: clinical associations and outcome. Plasma Exchange/Sandoglobulin Guillain-Barré Syndrome Trial Group. Ann Neurol. 1998; 44(5): 780-8. doi: 10.1002/ana.410440512. PMID: 9818934.

15) Hughes RA. Treatment of Guillain-Barré syndrome with corticosteroids: lack of benefit? Lancet. 2004; 363(9404): 181-2. doi: 10.1016/S0140-6736(03)15367-6.

16) Hughes RA, Swan AV, Van Doorn PA. Intravenous immunoglobulin for Guillain-Barré syndrome. Cochrane Database Syst Rev. 2014; 9: CD002063. doi: 10.1002/14651858.cd002063.pub6.

17) Hughes RA, Newsome-Davis JM, Perkin GD, Pierce JM. Controlled trial prednisolone in acute polyneuropathy. Lancet. 1978; 312(8093): 750-3. doi: 10.1016/S0140-6736(78)92644-2.

18) Hughes RA, Pritchard J, Hadden RD. Pharmacological treatment other than corticosteroids, intravenous immunoglobulin and plasma exchange for Guillain-Barré syndrome. Cochrane Database Syst Rev. 2011; (3): CD008630. doi: 10.1002/14651858.cd008630.pub2. PMID: 21412923.

19) Sejvar JJ, Baughman AL, Wise M, Morgan OW. Population incidence of Guillain-Barre' syndrome: a systematic review and meta-analysis. Neuroepidemiol. 2011; 36(2): 123-33. doi: 10.1159/000324710. PMID: 21422765.

20) Kalra V, Sankhyan N, Sharma S, Gulati S, Choudhry R, Dhawan B. Outcome in childhood Guillain-Barré syndrome. Indian J Pediatr. 2009; 76(8): 795-9. doi: 10.1007/s12098-009-0125-y. PMID: 19381495.

21) Lee JH, Sung IY, Rew IS. Clinical presentation and prognosis of childhood Guillain-Barré syndrome. J Paediatr Child Health. 2008; 44(7-8): 449-54. doi: 10.1111/j.1440-1754.2008.01325.x. PMID: 18557809.

22) Verma R, Chaudhari TS, Raut TP, Garg RK. Clinico-electrophysiological profile and predictors of functional outcome in Guillain-Barre syndrome (GBS). J Neurol Sci. 2013; 335(1-2): 105-11. doi: 10.1016/j.jns.2013.09.002. PMID: 24064258.

23) Tekgul H, Serdaroglu G, Tutuncuoglu S. Outcome of axonal and demyelinating forms of Guillain-Barré syndrome in children. Pediatr Neurol. 2003; 28(4): 295-9. doi: 10.1016/S0887-8994(02)00626-4. PMID: 12849884.

24) Dahbour SS. Clinical experience with Guillain-Barre syndrome over a 6-year period in one hospital in the Middle East. Jordan Med J. 2009; 43(4): 280-5.

25) Benamer HT, Bredan A. Guillain-Barré syndrome in Arab countries: a systematic review. J Neurol Sci. 2014; 343(1-2): 221-3. doi: 10.1016/j.jns.2014.05.065. PMID: 24950899.

26) Korinthenberg R, Schessl J, Kirschner J. Clinical presentation and course of childhood Guillain-Barre syndrome: a prospective multicentre study. Neuropediatrics. 2007; 38(1): 10-7. doi: 10.1055/s-2007981686. PMID: 17607598.

27) Ruts L, Drenthen J, Jacobs BC, Van Doorn PA. Distinguishing acute-onset CIDP from fluctuating Guillain-Barré syndrome: a prospective study. Neurology. 2010; 74(21): 1680-6. doi: 10.1212/WNL.0b013e3181e07d14. PMID: 20427754.

28) AbdulJabbar MS. Pattern of Guillain-Barré syndrome in Saudi Arabia. J Trop Geogr Neurol. 1991; 1: 35-8.

29) Lin JJ, Hsia SH, Wang HS, Lyu RK, Chou ML, Hung PC, et al. Clinical variants of Guillain-Barré syndrome in children. Pediatr Neurol. 2012; 47(2): 91-6. doi: 10.1016/j.pediatrneurol.2012.05.011. PMID: 22759683. 